\title{
@@ OPENACCESS BARRIERS TO MENTAL HEALTHCARE IMPROVEMENT IN LOW AND MIDDLE INCOME COUNTRIES
}

\author{
Muhammad Irfan
}

Address for correspondence: Muhammad Irfan Department of Mental Health, Psychiatry and Behavioral Sciences, Peshawar Medical College, Riphah International University, Islamabad-Pakistan.

E-mail: mirfan78@yahoo.com

This article may be cited as Irfan M. Barriers to mental healthcare improvement in low and middle income countries. J Postgrad Med Inst. 2021; 35(3): 129-30. https://doi.org/10.54079/ jpmi.2021.35.3.3036
The quality of mental health treatment in low and middle-income countries is a source of concern despite publications claiming that mental healthcare is improving. ${ }^{1}$ Despite the presence of available evidence, that mental healthcare service development has been slow in pace in most of the developing countries. ${ }^{2}$ There are various mental health barriers which need to be addressed at this point to overall improve the services improve the delivery of mental health services.

Low priority on public health agenda: Mental health has a low priority on national and international public-health agendas, as evidenced by their low visibility in Millennium Development Goals (MDG) and Sustainable Development Goals (SDGs), ${ }^{3,4} \mathrm{~A}$ higher prominence on domestic and international agendas is necessary not just for increased funding, but also for gaining political support for the tough choices that typically accompany mental health reforms due to lack of consensus among stakeholders which leads to contradictory messages turning donors and policymakers off. The imminent needs are not prioritized on specialist services. Communication is not clear with decision makers and mental health professionals. ${ }^{5}$ It is also a matter of great concern that lack of public interest in the wellbeing of those with mental disorders may be due to the stigma associated. ${ }^{6-8}$ Decision-makers' erroneous belief that mental health treatment is not as cost-effective as the care for a variety of the other physical disorders. ${ }^{9,10}$

Disorganization of services: The greatest impediment to decentralization and systematic disenfranchisement is the entrenched interests of mental health and hospital staff, who fear losing their power base and being compelled to relocate to rural regions. Service consumers and family organizations frequently support the old system because they are ignorant of the benefits. ${ }^{11}$ In a nutshell, a homogenous model of services that must be available for everyone that may prioritizes nurturing and replenishing mental health services in primary care setting that can best serve individuals who suffer from mental illnesses, is missing.
Dearth of mental health work force: Only a few people pursue mental healthcare as a profession, thus there aren't enough people qualified to provide it. ${ }^{12}$ Higher pay in private practise and abroad, on the other hand, incentivize even this workforce to quit government employment or even the nation leading to brain drain. Furthermore, there are little incentives for mental health specialists to remain in rural areas, where the majority of the country's population resides. To diversify the workforce, flexibility and creativity is required, including increase in the number of mental health training programs for working professionals in accordance with authorities' guidelines and regulations. As a result, the function of a mental health practitioner in the community is expected to shift from clinical care provider to ongoing trainer and supervisor. ${ }^{2}$

Lack of effective leadership in public health: Most Mental health leaders in low and middle income countries lack public health abilities, and there is a paucity of mental health leaders with public-health training. Senior mental health professionals who are promoted to national mental health leaders frequently focus on individual therapeutic care rather than community-oriented actions. ${ }^{2}$ Few colleges across the world provide public mental health courses to prepare future mental health administrators, planners, and leaders. There are just a few international training and exchange options for leaders to improve their public mental health skills. ${ }^{2}$

Natural and Man-made Disasters: A recent hurdle in developing countries like Pakistan has been the issues related to natural and man-made disasters including drought, fires, accidents, earthquake, floods and terrorism. ${ }^{13}$ This is harming not just the country's economy, but the ever-changing dynamics of the situation are making it difficult for the general populace to settle and adjust to the circumstances, rendering them vulnerable to mental health problems. This disruption is aggravating existing mental healthcare issues, as there is no coverage for this additional percentage of the population. 
Imperfection of Mental Health Information System: Lacunae in the information system is a hurdle in providing just and and equitable mental health services and this has a general impact on all areas of mental health service provision. ${ }^{14}$

Inappropriate Legislation: Inappropriate legislation and enforcement of existing laws is a major challenge for health systems in developing countries. ${ }^{15}$

The need of the day is to establish psychiatric treatment services in general hospitals and the development of mental healthcare in primary care and other health-care settings for societal and communal needs. Also, international cooperation is needed along with local and national efforts to overcome the barriers. In addition, advocacy for persons with mental illnesses may shape political will which has the capacity to increase the chances of availability and access to humane mental health treatment. For the development of community mental health services, in addition to the emphasis on the inclusion of mental health in primary care, services at the secondary care level should be prioritized in the community taking all stakeholders on board.

\section{REFERENCES}

1. Patel V, Araya R, Chatterjee S, Chisholm D, Cohen A, De Silva M et al. Treatment and prevention of mental disorders in low-income and middle-income countries. Lancet. 2007; 370:991-1005. DOl: 10.1016/S0140-6736(07)612409.

2. Saraceno $B$, van Ommeren $M$, Batniji $\mathrm{R}$, Cohen $\mathrm{A}$, Gureje 0 , Mahoney
$\mathrm{J}$, et al. Barriers to improvement of mental health services in low-income and middle-income countries. Lancet. 2007;370:1164-74. DOI: : 10.1016/ S0140-6736(07)61263-X.

3. Prince $M$, Patel $V$, Saxena $S$, Maj M, Maselko J, Phillips MR, et al. No health without mental health. Lancet. 2007;370:859-77. DOl: 10.1016/ S0140-6736(07)61238-0.

4. Sachs JD. From millennium development goals to sustainable development goals. Lancet. 2012; 379(9832):2206-11. D0I: 1016/S0140-6736(12)60685-0

5. Sartorius N, Kaelber CT, Cooper JE, Roper MT, Rae DS, Gulbinat W, et al. Progress toward achieving a common language in psychiatry. Results from the field trial of the clinical guidelines accompanying the WHO classification of mental and behavioral disorders in ICD-10. Arch Gen Psychiatry. 1993; 50:115-24. DOI: 10.1001/archpsyc.1993.01820140037004.

6. Gureje 0, Lasebikan V0, Ephraim-Oluwanuga 0 , Olley BO, Kola L. Community study of knowledge of and attitude to mental illness in Nigeria. Br J Psychiatry. 2005; 186: 436-41. D0l: 10.1192/ bjp.186.5.436.

7. Raguram R, Weiss MG, Channabasavanna SM, Devins GM. Stigma, depression, and somatization in South India. Am J Psychiatry. 1996; 153: 1043-9. DOI: 10.1176/ajp.153.8.1043.

8. Littlewood R, Jadhav S, Ryder AG. A cross-national study of the stigmatization of severe psychiatric illness: historical review, methodological considerations and development of the questionnaire. Transcult Psychiatry. 2007; 44:171-202. DOI:
10.1177/1363461507077720.

9. World Health Organization. Economic aspects of the mental health system: key messages to health planners and policy-makers. Geneva, Switzerland: World Health Organization, 2006.

10. Hyman S, Chisholm D, Kessler R, Patel V, Whiteford H. Mental Disorders. In: Jamison D, Breman J, Measham A, eds. Disease control priorities in developing countries (2nd Edition). New York, USA: Oxford University Press, 2006.

11. Gurung D, Upadhyaya N, Magar J, Giri NP, Hanlon C, Jordans MJD. Service user and care giver involvement in mental health system strengthening in Nepal: a qualitative study on barriers and facilitating factors. Int $\mathrm{J}$ Ment Health Syst. 2017; 11: 30. DOI: 10.1186/s13033-017-0139-1

12. World Health Organization. World Health Report 2006; working together for health. World Health Organization: Geneva, 2006.

13. Swiss Re. Natural catastrophes and man-made disasters in 2015: Asia suffers substantial losses. Zurich, Switzerland: Swiss Reinsurance Company Ltd., 2016.

14. Taghva A, Farsi Z, Javanmard Y, Atashi A, Hajebi A, Khademi M. Stigma barriers of mental health in Iran: A qualitative study by stakeholders of mental health. Iran J Psychiatry. 2017;12(3):163-71.

15. Zhang $\mathrm{QE}, \mathrm{Ng} \mathrm{CH}$, Ungvari GS, Van $\mathrm{IK}$, Wang G, Xiang YT. Mental health-care delivery for older people in China: An update of challenges and recent clinical research. Los Angeles: SAGE Publications Sage CA, 2019.
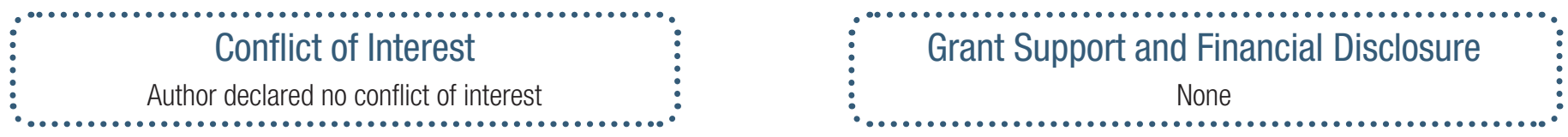